\title{
OPTIMASI SUDUT HUB PADA TURBIN ANGIN HORISONTAL DUA SUDU
}

\author{
${ }^{(1)}$ Muhammad Irfansyah, ${ }^{(2)}$ Muhammad Firman \\ ${ }^{(1)(2)}$ Prodi Teknik Mesin, Fakultas Teknik Universitas Islam Kalimantan MAB \\ Jl. Adyaksa No.2 Kayu Tangi Banjarmasin \\ Email : irfanuniska@yahoo.co.id, firmanuniska99@gmail.com
}

\begin{abstract}
ABSTRAK
Penelitian ini bertujuan untuk mempelajari pengaruh sudut hub pada turbin angin dua sudu. Sudut bagian hub sangat perpengaruh terhadap permulaan putaran (starting) turbin angin horisontal. Modifikasi dilakukan dengan menambahkan lapisan tambahan kayu pada bagian atas sehingga akan menambah besar sudut pada bagian hub tersebut.

Metode yang digunakan pada penelitian ini adalah kegiatan perancangan, pembuatan, modifikasi, dan pengujian sudu turbin. Bahan pembuatan sudu digunakan 2 buah material kayu meranti merah ukuran 1300x160x40 mm. Rancangan pertama menggunakan sudut hub $14^{\circ}$, sedangkan rancangan kedua yang dimodifikasi akan menambah sudut hub menjadi $26^{\circ}$. Variasi kecepatan angin sebesar $1,2,3,4,5,6 \mathrm{~m} / \mathrm{s}$. Alat ukur yang digunakan adalah anemometer dan tachometer digital.

Dari hasil penelitian, pada kecepatan angin $1,9 \mathrm{~m} / \mathrm{s}$, sudu dengan sudut hub $14^{\circ}$ mengahasilkan putaran poros $48 \mathrm{rpm}$, dan sudu dengan sudut hub $26^{\circ}$ menghasilkan putaran poros $107 \mathrm{rpm}$. Sedangkan pada kecepatan angin $6,8 \mathrm{~m} / \mathrm{s}$, sudu dengan sudut hub $14^{\circ}$ mengahasilkan putaran poros $234 \mathrm{rpm}$, dan sudu dengan sudut hub $26^{\circ}$ menghasilkan putaran poros $368 \mathrm{rpm}$.
\end{abstract}

Kata kunci : Modifikasi hub, Sudu, Turbin Angin.

\section{PENDAHULUAN}

Energi listrik merupakan salah satu energi yang banyak digunakan saat ini. Perkembangan teknologi dan ilmu pengetahuan telah mendorong penggunaan tenaga listrik pada semua aspek kehidupan manusia, baik untuk keperluan industri, rumah tangga maupun perkantoran. Selama ini sumber energi listrik banyak didapatkan dari hasil konversi energi fosil seperti minyak bumi, batu bara dan gas. Jumlah energi fosil ini makin lama semakin berkurang dan kecenderungan harganya akan terus naik, sehingga perlu dicarikan sumber energi alternatif untuk membangkitkan energi listrik. Sumber energi terbarukan, seperti tenaga angin, tenaga surya, tenaga ombak, mikrohidro dan biomassa merupakan sumber energi alternatif untuk pembangkit listrik di masa depan.
Energi angin adalah salah satu sumber energi terbarukan yang banyak digunakan secara luas dalam aplikasi skala kecil dan menjanjikan untuk pengembangan dan penelitian dalam skala besar, sebagai peralatan turbin angin yang dibuat dengan harga yang murah. Pembangkit listrik tenaga angin bekerja dengan cara merubah secara langsung energi angin menjadi listrik. Efek positif dari pembangkit listrik tenaga angin adalah bebas dari polusi lingkungan.

Telah banyak riset yang dilakukan untuk meningkatkan performansi pembangkit listrik tenaga angin. Tulus Setiawan dan Teng Sutrisno (2015), meneliti tentang studi numerik karakteristik axial turbin akibat penambahan tip blade. Idzani Muttaqin dan Budi Hartadi (2015) meneliti tentang perbandingan turbin angin 
p-ISSN 2502-4922,e-ISSN 2615-0867

untuk pembangkit listrik dengan kapasitas 450W.

Berdasarkan latar belakang diatas, dipandang perlu untuk meneliti sudut bagian pangkal ( $h u b$ ) turbin angin horisontal dua sudu, dengan membandingkan sudut bagian pangkal (hub) sebelum dimodifikasi dan setelah dimodifikasi, sehingga turbin dapat digunakan pada daerah kecepatan angin yang rendah.

\section{METODE PENELITIAN}

Metode yang digunakan pada penelitian ini adalah kegiatan perancangan, pembuatan, modifikasi, dan pengujian sudu turbin. Bahan pembuatan sudu digunakan 2 buah material kayu meranti merah ukuran 1300x160x40 mm. Rancangan pertama menggunakan sudut hub $14^{\circ}$, sedangkan rancangan kedua yang dimodifikasi akan menambah sudut hub menjadi $26^{\circ}$. Variasi kecepatan angin sebesar 1.9, 2.2, 4.1, 6.4, 6,8 m/s. Alat ukur yang digunakan adalah anemometer dan tachometer digital. Penelitian ini dilakukan dengan empat tahap, yaitu: (1). pengumpulan data, (2). pengujian alat, (3) analisis data, (4) kesimpulan hasil penelitian.

\section{HASIL DAN PEMBAHASAN}

Hasil pengujian prototipe turbin diameter 1,3 m dengan sudu 2, model A dengan sudut hub $16^{\circ}$ dan model $\mathrm{B}$ dengan sudut hub $26^{\circ}$, dengan variasi kecepatan angin 1.9, 2.2, 4.1, 6.4, 6,8 $\mathrm{m} / \mathrm{s}$, sebagai berikut:

Tabel 1. Data Pengujian Sudu dengan Variasi sudut Hub

\begin{tabular}{|c|c|c|c|c|c|}
\hline $\begin{array}{c}\text { Kecepatan } \\
\text { Angin } \\
(\mathrm{m} / \mathrm{s})\end{array}$ & 1,9 & 2,2 & 4,1 & 6,4 & 6,8 \\
\hline $\begin{array}{c}\text { Putaran } \\
\text { poros } \\
\text { teorotis } \\
\text { (rpm) }\end{array}$ & 176,50 & 204,37 & 380,87 & 594,53 & 631,69 \\
\hline
\end{tabular}

\begin{tabular}{|c|c|c|c|c|c|}
\hline $\begin{array}{c}\text { Putaran } \\
\text { poros } \\
\text { dengan } \\
\text { Sudut Hub } \\
14^{\circ}(\mathrm{rpm})\end{array}$ & 48 & 57 & 91 & 201 & 234 \\
\hline $\begin{array}{c}\text { Putaran } \\
\text { poros } \\
\text { dengan } \\
\text { Sudut Hub } \\
26^{\circ}(\mathrm{rpm})\end{array}$ & 107 & 136 & 240 & 331 & 368 \\
\hline
\end{tabular}

Grafik 1. Perbandingan putaran poros teoritis, sudut hub $14^{\circ}$, sudut hub $26^{\circ}$

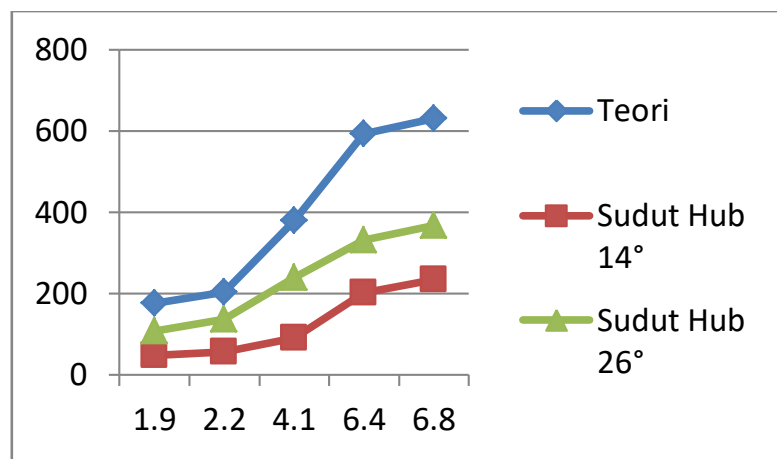

Dari grafik 1. diatas, terjadi peningkatan putaran poros pada variasi kecepatan angin. Semakin cepat kecepatan angin maka akan semakin cepat putaran poros yang dihasilkan. Pengaruh sudut hub pada sudu dengan sudut $14^{\circ}$ pada kecepatan angin $1,9 \mathrm{~m} / \mathrm{s}$ menghasilkan putaran poros $48 \mathrm{rpm}$, dan pada kecepatan angin $6,8 \mathrm{~m} / \mathrm{s}$ menghasilkan putaran poros $234 \mathrm{rpm}$. Sedangkan pada sudut hub $26^{\circ}$, pada kecepatan angin 1,9 m/s menghasilkan putaran poros $107 \mathrm{rpm}$, dan pada kecepatan angin $6,8 \mathrm{~m} / \mathrm{s}$ menghasilkan putaran poros $368 \mathrm{rpm}$. Pada putaran poros perhitungan teori kecepatan angin $1,9 \mathrm{~m} / \mathrm{s}$ menghasilkan putaran poros $176,50 \mathrm{rpm}$, dan pada kecepatan angin $6,8 \mathrm{~m} / \mathrm{s}$ menghasilkan putaran poros 631,69 rpm.

\section{KESIMPULAN}

Hasil pengujian optimasi dapat disimpulkan sebagai berikut:

1. Daya maksium turbin hasil perancangan 391 Watt dengan diameter $1,3 \mathrm{~m}$. 
2. Pengaruh sudut hub pada sudu dengan sudut $14^{\circ}$ pada kecepatan angin $1,9 \mathrm{~m} / \mathrm{s}$ menghasilkan putaran poros $48 \mathrm{rpm}$, dan pada kecepatan angin $6,8 \mathrm{~m} / \mathrm{s}$ menghasilkan putaran poros $234 \mathrm{rpm}$. Sedangkan pada sudut hub $26^{\circ}$, pada kecepatan angin $1,9 \mathrm{~m} / \mathrm{s}$ menghasilkan putaran poros $107 \mathrm{rpm}$, dan pada kecepatan angin $6,8 \mathrm{~m} / \mathrm{s}$ menghasilkan putaran poros $368 \mathrm{rpm}$. Pada perhitungan teori kecepatan angin $1,9 \quad \mathrm{~m} / \mathrm{s}$ menghasilkan putaran poros 176,50 rpm, dan pada kecepatan angin 6,8 $\mathrm{m} / \mathrm{s}$ menghasilkan putaran poros 631,69 rpm.

3. Antara sudut hub $24^{\circ}$ dan sudut hub $26^{\circ}$ yang dimodifikasi, terjadi peningkatan putaran poros turbin.

Dari kesimpulan diatas dapat disarankan agar penelitian selanjutnya untuk meneliti pengaruh perubahan sudut pada bagian ujung sudu (tip). Pengaruh perubahan sudut pada bagian tengah sudu. Atau pengaruh kombinasi perubahan sudut gabungan tip, tengah dan bagian pangkal (hub).

\section{REFERENSI}

[1] 2015, Prosiding Seminar Nasional Teknik Mesin 10, Universitas Kristen Petra Surabaya, BKSTM Indonesia.

[2] Abdul Kadir, 1982, Energi, Sumber Daya, Inovasi, Tenaga Listrik, Potensi Ekonomi, Universitas Indonesia, Jakarta.

[3] Archie W. Culp, 2003, Prinsipprinsip Konversi Energi, Erlangga, Jakarta.

[4] Francis M. Vanek, 2008, Energy System Engineering : Evaluation \& Implementation, Mc Graw Hill, USA.

[5] Gerry Van Klinken, 2001, Energi Dalam Masyarakat Modern, Satya Wacana, Semarang.
[6] http://www.id.wikipedia.org/wiki/Tu rbin angin, (judul turbin angin, di akses tanggal 16 Pebruari 2014).

[7] Hugh Piggott,1997, Wind power Workshop, Certer for Alternative Publications, British Wind Energy Association, England.

[8] Jurnal Al Ulum, Volume 50 Nomor 4, Oktober 2011, ISSN 1411-1403, Universitas Islam Kalimantan Muhammad Arsyad Al Banjary Banjarmasin.

[9] Jurnal Teknologi Dirgantara, Volume 6 No. 2 Desember 2008, ISSN 1412-8063, Lembaga Penerbangan dan Antariksa Nasional (LAPAN), Jakarta.

[10] Tony Burton, 2001, Wind Energy Handbook, John Wiley \& Sons, Ltd Baffins Lane, Chichester, West Sussex, England. 